\title{
P2X receptors in Aplysia californica: Chemosensory systems, bio- energetic and development
}

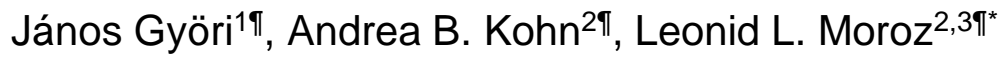

ף-equal contribution

${ }^{1}$ Centre for Ecological Research, Department of Experimental Zoology, Balaton Limnological Institute, H-8237 Tihany, Hungary; ${ }^{2}$ Whitney Laboratory for Marine Bioscience, University of Florida, St.Augustine, FL, 32080,USA; ${ }^{3}$ Departments of Neuroscience and McKnight Brain Institute, University of Florida, Gainesville, FL, 32610,USA.

${ }^{*}$ Corresponding author

Emails:moroz@whitney.ufl.edu

https://orcid.org/0000-0002-1333-3176 


\begin{abstract}
:
ATP and its ionotropic P2X receptors are components of one of the most ancient signaling systems. However, little is known about the distribution and function of purinergic transmission in invertebrates. Here, we cloned, expressed, and pharmacologically characterized P2X receptors in the sea slug Aplysia californica - a prominent model in cellular and system neuroscience. We showed that ATP and P2X receptors are essential signaling components within the unique bioenergetic center located in the CNS of Aplysia, also known as the cerebral F-cluster of insulincontaining neurons. Functional P2X receptors were successfully expressed in Xenopus oocytes to characterize their ATP-dependence $\left(\mathrm{EC}_{50}=306 \mu \mathrm{M}\right)$, two-phased kinetics, ion selectivity $\left(\mathrm{Na}^{+}-\right.$ dependence), sensitivity to the ATP analog Bz-ATP ( 20\% compare to ATP) and antagonists (with PPADS as a more potent inhibitor compared to suramin). Next, using RNA-seq, we characterized the expression of P2X receptors across more than a dozen Aplysia peripheral tissues and developmental stages. We showed that $\mathrm{P} 2 \mathrm{X}$ receptors are predominantly expressed in chemosensory structures and during early cleavage stages. The localization and pharmacology of P2X receptors in Aplysia highlight the evolutionary conservation of bioenergetic sensors and chemosensory purinergic transmission across animals. This study also provides a foundation to decipher homeostatic mechanisms in development and neuroendocrine systems.
\end{abstract}

Keywords: P2X receptors; Bio-energetics; Mollusca; Evolution of Neurotransmitters; Homeostasis; Ion channels; Developments 


\section{Graphical Abstract:}

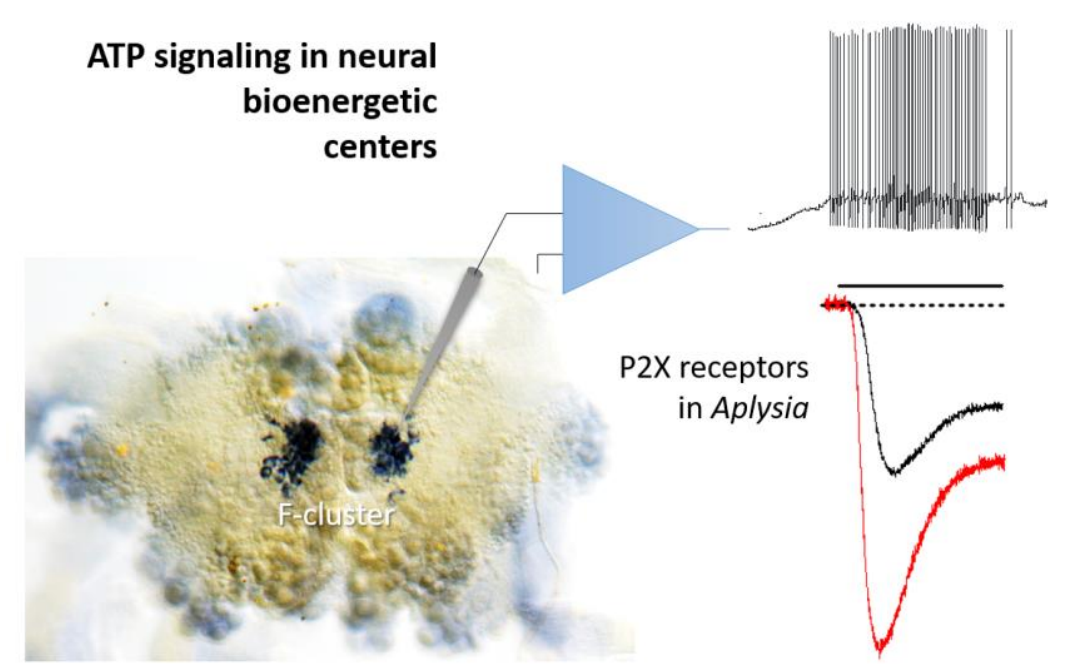

We show that ATP and its ligand-gated P2X receptors are essential signaling components within both the chemosensory systems and the unique bioenergetic center, present in the CNS of the sea slug Aplysia californica - a prominent model in neuroscience. Expression and pharmacology of P2X receptors in Aplysia confirms the preservation of evolutionary conserved bioenergetic sensors across animals and provide new tools to decipher homeostatic mechanisms in neuro-endocrine systems in general. 


\section{Introduction}

In addition to being the critical energy storage for every cell, ATP acts as one of the most ancient intracellular and intercellular signal molecules[1,2]. The possible involvement of ATP in signaling mechanisms was initiated in the 1920s by Drury and Szent-Gyorgyi[3]; and then in the 1950s by Holtons [4-6], leading to the concept of purinergic transmission[7,8]. Eventually, rapid ATP-gated ion currents were discovered in neurons[9,10] and muscles[11], and specific subtypes of the ligand-gated $\mathrm{P} 2 \mathrm{X}$ receptors were identified in the 1990s[12-16].

Comparative studies established that P2X-type receptors are broadly distributed across many eukaryotic lineages[1,17-20], including the majority of Metazoa[2,13,2124]. Nevertheless, the recruitment of P2X receptors into different signaling mechanisms and tissues occurred relatively randomly, and, in some evolutionary lineages, P2X receptors were secondarily lost. For example, Drosophila and $C$. elegans genomes have no $\mathrm{P} 2 \mathrm{X}$ receptors[25], but other ecdysozoans such as Daphnia, the shrimp Litopenaeus, the tick Boophilus[26] and tardigrades[27] contain one receptor. Many studied Lophotrochosoans, including molluscs and flatworms, also have one type of $\mathrm{P} 2 \mathrm{X}$ receptor with shared pharmacological properties to mammals[28]. However, practically nothing is known about the functional roles of $\mathrm{P} 2 \mathrm{X}$ receptors in the CNS and peripheral tissues of invertebrates and molluscs, in particular.

The release of ATP from the central ganglia of the pond snail, Lymnaea stagnalis was demonstrated[29], and, subsequently, $\mathrm{P} 2 \mathrm{X}$ receptors were identified in this species with widespread expression across the CNS[30], but unknown function(s).

Here, we show that ATP and its ligandgated $\mathrm{P} 2 \mathrm{X}$ receptors are essential signaling components within chemosensory structures and the unique bioenergetic center, present in the CNS of the sea slug Aplysia - a prominent model in neuroscience[31-36]. Expression and pharmacology of $\mathrm{P} 2 \mathrm{X}$ receptors in Aplysia confirms the preservation of evolutionary conserved bioenergetic reporter-sensor systems across animals and provide new tools to decipher homeostatic mechanisms in neuroendocrine systems and development.

\section{Materials and methods}

2.1. Cloning of Aplysia AcP2X receptors for expression, in situ hybridization and molecular analyses

Aplysia californica (60-100g) were obtained from the National Resource for Aplysia at the University of Miami (Supplementary Data section\#1 for details).

The original sequences were generated using RNA-seq profiling[37-40]. Details for RNA extraction and cDNA library construction have been described[37-39,41] and provided in Supplementary Data. We used the same protocols for whole-mount in situ hybridization as reported elsewhere[42,43] with a specific probe for the validated $A c \mathrm{P} 2 \mathrm{X}$ (Supplementary Data section\#2). Expression of $A c \mathrm{P} 2 \mathrm{X}$ was performed in eight experimental and two control preparations of the CNS; additional controls were reported elsewhere[37,43]. Control in situ hybridization experiments with full length 'sense' probes revealed no specific or selective staining under identical labeling protocols. Images were acquired with a Nikon Coolpix4500 digital camera mounted on an upright Nikon Optiphot-2 microscope.

Expression levels of transcripts were calculated using the normalization method for RNA-seq - Transcripts Per Million (TPM)[44]. Mapping was performed in the STAR (2.3.0)/feature Counts analysis with the values obtained from the Bowtie2/Tophat 
pipeline[45]. The mapped reads were summarized and counted within the $R$ statistical programming language. Supplementary Methods Section\#3 contains a list of SRA RNA-seq projects.

\subsection{Oocyte expression and electrophysiology}

RNA and oocyte preparation. RNA was transcribed from full-length cDNAs of Ac $\mathrm{P} 2 \mathrm{X}$ subunits using the $\mathrm{T}_{7}$ mMessage mMachine in vitro transcription kit (Ambion). The amount of purified, transcribed RNA was estimated on a Bioanalyzer (Agilent). Surgically removed stage V and VI oocytes from Xenopus laevis were injected with a total of 50ng transcribed RNA (46nL total volume) and incubated at $17^{\circ} \mathrm{C}$ for three-five days in ND96 medium (96mM NaCl, 2mM KCl, $1 \mathrm{mM} \mathrm{MgCl}_{2}$, $1.8 \mathrm{mM} \mathrm{CaCl}_{2}$, and $5 \mathrm{mM}$ HEPES, $\mathrm{pH}=7.4$ ) supplemented with $2.5 \mathrm{mM}$ sodium pyruvate, 100units/mL penicillin, $\quad 100 \mu \mathrm{g} / \mathrm{mL}$ streptomycin, and 5\% horse serum (Sigma).

Oocytes recordings. The oocyte recording bath was in ND96 medium $(96 \mathrm{mM}$ $\mathrm{NaCl}, 2 \mathrm{mM} \mathrm{KCl}, 1 \mathrm{mM} \mathrm{MgCl}_{2}, 1.8 \mathrm{mM}$ $\mathrm{CaCl}_{2}$, and $5 \mathrm{mM}$ HEPES, $\mathrm{pH}=7.4$ ) with the $1.8 \mathrm{mM} \mathrm{CaCl} 2$ being replaced by $1.8 \mathrm{mM}$ $\mathrm{BaCl}_{2}$. Whole-oocyte currents were recorded by two-electrode voltage clamp (GeneClamp500B, Axon Instruments, Foster City, CA, USA) using microelectrodes made of borosilicate glass (WPI, USA) with a resistance of $0.5-1 \mathrm{M} \Omega$ when filled with $2.5 \mathrm{M}$ $\mathrm{KCl}$. Currents were filtered at $2 \mathrm{kHz}$ and digitally sampled at $5 \mathrm{kHz}$ with a Digidata 1320B Interface (Axon Instruments, CA). Recording and data analysis were performed using pCLAMP software version 8.2 (Axon Instruments). For data acquisition and clamp protocols, the amplifiers were connected via a Digidata 1320B AD/DA converter (Axon, USA) to an AMD PC with pClamp 8.2 voltage-clamp software (Axon, USA). Unfiltered signals were sampled at $10 \mathrm{kHz}$ and stored digitally.
Data are presented as mean \pm S.E. using Student's paired $t$-test. Concentrationresponse data were fitted to the equation $\mathrm{I}=\mathrm{I}_{\max } /\left[1+\left(\mathrm{EC}_{50} / \mathrm{L}\right)^{n H}\right]$, where $\mathrm{I}$ is the actual current for a ligand concentration $(\mathrm{L}), n_{H}$ is the Hill coefficient, $I_{\max }$ is the maximal current and $\mathrm{EC}_{50}$ is the concentration of agonist evoking 50\% the maximum response. To compute the reversal potential for sodium the Nernst equation used; $\mathrm{Vj}=(\mathrm{RT}) /(\mathrm{zF}) \ln (\mathrm{c} 1 / \mathrm{c} 2)$ where $\mathrm{R}$ is the gas constant 1:98 $\mathrm{calK}^{-1} \mathrm{~mol}^{-1}, \mathrm{~F}$ is the Faraday constant $96,840 \mathrm{C} / \mathrm{mol}$, $\mathrm{T}$ is the temperature in ${ }^{\circ} \mathrm{K}$ and $\mathrm{z}$ is the valence of the ion.

In situ recordings. Voltage- and current-clamp experiments were carried out on identified F-cluster neurons in intact nervous systems of Aplysia[46]. $\sim 0.5 \mathrm{~mL}$ bath was perfused with solutions using a gravityfeed system and a peristaltic pump, and solution exchanges were performed by VC-6 six-channel valve controller (Warner Inst., USA). Conventional two-electrode (3$10 \mathrm{M} \Omega$ ) voltage-clamp techniques (Axoclamp2B, TEVC mode) were employed to measure agonist-activated currents as reported[47] at room temperature $\left(20 \pm 2^{\circ} \mathrm{C}\right)$. To characterize membrane and action potentials, we used a bridge mode of Axoclamp2B with borosilicate microelectrodes (tip resistance:10-18M $\Omega$, with $0.5 \mathrm{M} \mathrm{KCl}, 2 \mathrm{M} \mathrm{K}$-Acetate, and $5 \mathrm{mM}$ HEPES, $\mathrm{pH}=7.2$ ).

\section{Results}

3.1 Identity, phylogeny and tissuespecific expression of Aplysia $P 2 X$ receptors

In Aplysia, we identified and cloned a single $\mathrm{P} 2 \mathrm{X}$ receptor with two splice forms (GenBank\#\#: NP_001191558.1, NP_001191559.1), which shared 92\% identity (Supplementary Data). The predicted structure of the Aplysia $\mathrm{P} 2 \mathrm{X}$ reveals all major evolutionary conservative sites and posttranslational modifications 
(Supplementary Data, Fig. 1S), which are similar to its homolog in another gastropod, Lymnaea[30]. The genomic organization of the $\mathrm{P} 2 \mathrm{X}$ receptors confirmed the overall evolutionary conservation of exons and intron-exon boundaries. Aplysia P2X receptor exons are similar in number and length to other vertebrate $\mathrm{P} 2 \mathrm{X} 4$ receptors, but this is not true in some other invertebrates (Supplementary Data and Fig. 2S).

Fig. 1A shows the phylogenetic relationships among $\mathrm{P} 2 \mathrm{X}$ receptors with prominent events of gene duplications in the lineages leading to humans, zebrafishes, hemichordates, echinoderms, and basallybranched metazoans such as sponges, placozoans, and cnidarians. In contrast, representatives of molluscs (including Aplysia), annelids, parasitic flatworms (Schistosoma) seem to have a single copy of $\mathrm{P} 2 \mathrm{X}$-encoded genes, which often form distinct phyletic clusters within a respective phylum. This reconstruction suggests the presence of a single P2X gene in the common metazoan ancestor with independent multiplication events in selected animal lineages. It primarily occurred within vertebrates as the reflection of whole-genome duplications early in the evolution of this group). Interestingly, some bilaterians (such as the acoel Hofstenia miamia, insects, and nematodes[48]) secondarily lost P2X receptors. Such mosaic-type phyletic distribution likely illustrates different system constraints for the recruitment of $\mathrm{P} 2 \mathrm{X}$ receptors to novel functions and/or preservation of ancestral molecular mechanisms of purinergic signaling.

Next, we characterized the expression of P2X receptors in Aplysia using a broad spectrum of RNA-seq data obtained from adult and developmental stages[49] (see Supplementary Data section 3 for details).

The highest level of P2X expression was found in the chemosensory structures (the mouth area and rhinophores[50]) as well as in the gill (Fig. 1B), which is also known as the chemosensory and respiratory organ. Expression of P2X receptors was also detected in the majority of peripheral organs of Aplysia as well as during the first cleavage stages (Fig. 1B), where no neurons or specialized sensory cells exist. Thus, ATP could act as a paracrine messenger in early embryogenesis.

Interestingly, the CNS had the overall lowest level of the P2X gene expression (Fig. 1B). This situation might be analogous to the recruitment of purinergic signaling in the chemosensation within the mammalian brain[51], suggesting the presence of a distinct population of ATP-sensing cells. We tested this hypothesis.

$A c \mathrm{P} 2 \mathrm{X}$ was explicitly expressed in two symmetrical subpopulations of insulincontaining neurons (Fig. 2A, n=6) localized in the F-cluster in the cerebral ganglion of Aplysia[46,52]. Each subpopulation contained about 25-30 of electrically coupled cells $(30-50 \mu \mathrm{m}$ diameter, Fig. 2A-B)[46]. Application of $2 \mathrm{mM}$ ATP to these neurons elicited a $2-5 \mathrm{mV}$ depolarization, action potentials, and these effects were reversible (Fig. 2C) and voltage-dependent (Fig. 2D). Neurons that were negative for $A c \mathrm{P} 2 \mathrm{X}$, by in situ hybridization, showed no response to as high as $10 \mathrm{mM}$ ATP concentration. These tests confirmed that $\mathrm{P} 2 \mathrm{X}$ receptors in $\mathrm{F}$ cluster neurosecretory cells are functional.

\subsection{Expression of $A c P 2 X$ in Xenopus oocyte confirms the evolutionary conservation of kinetic and pharmacological parameters \\ ATP elicited an inward current in a} concentration-dependent manner in oocytes injected with $A c \mathrm{P} 2 \mathrm{X}$ (Fig. 3A). $\mathrm{EC}_{50}$ s were determined for both the fast ( $0-1$ seconds) and the slow component of current with continuous application of ATP. The $\mathrm{EC}_{50}$ for the fast component was $306.0 \mu \mathrm{M}$ with a 1.58 Hill coefficient and for the slow component 
497.4 $\mu$ M with a 0.97 Hill coefficient $(n=5$ oocytes, Fig. 3B). The second application of the agonist, with a recovery time of 6 minutes, generated a $15-30 \%$ reduction in peak amplitude and is indicative of the rundown observed in other $\mathrm{P} 2 \mathrm{X}$ receptor subunits. The response to $250 \mu \mathrm{M}$ ATP produced a mean peak amplitude of $31.3 \mathrm{nA} \pm 3.8 \mathrm{nA}$ and a time to a peak value of $2.76 \pm 0.21 \mathrm{~s}(\mathrm{n}=19)$ with a holding membrane potential (HP) of $-70 \mathrm{mV}$ (Fig. 3C). The ATP analog, 2',3'-O-(4-Benzoylbenzoyl) adenosine 5'-triphosphate (Bz-ATP[22]) gave a partial response at $20 \%$ of the ATP response ( $n=8$ oocyte, Fig. 3C). There were no UTP and ADP responses within the same range of concentrations (data not shown).

The current-voltage relationship was investigated in the presence of elevated (144mM) and low extracellular $\mathrm{NaCl}(96 \mathrm{mM})$ concentrations ( $\mathrm{n}=6$ oocytes, Fig. 3D). A reversal potential was determined by applying a ramp protocol from $-70 \mathrm{mV}$ to $20 \mathrm{mV}$ in high and normal $\mathrm{Na}^{+}$with $250 \mu \mathrm{M}$ of ATP (Fig. 3E). The reversal potential was $13.9 \mathrm{mV}$ and shifted by $+10.2 \pm 1.3 \mathrm{mV}$ to positive holding in high sodium solution $(n=6$ oocytes), according to the Nernst equation.

P2X antagonist suramin[22] inhibited ATP responses in a concentration-dependent manner (Fig. 4A,B; 7 oocytes,). Another P2X antagonist, pyridoxal-phosphate-6azophenyl-2',4-disulfonic acid(PPADS[22]) also inhibited the response of ATP on AcP2X in a concentration-dependent manner (Fig. 4C,D). However, the application of PPADS produced a greater block than the suramin (Fig. 4E). Mean current responses to $250 \mu \mathrm{M}$ ATP in the range of $1-250 \mu \mathrm{M}$ PPADS generated an $\mathrm{EC}_{50}=211.2 \mu \mathrm{M}$ for the fast component, but the slow component could not be calculated (5-7 oocytes, Fig. 4D). The second splice form of $A c \mathrm{P} 2 \mathrm{X}_{\mathrm{b}}$ was also expressed in oocytes producing currents very similar to the first isoform $A c \mathrm{P} 2 \mathrm{X}$ described above; however, it resulted in much smaller (and unstable) responses (data not shown).

\section{Discussion}

As the central bioenergetic currency, the intracellular concentrations of ATP reach $1-10 \mathrm{mM}$ with multiple mechanisms of its extracellular release across all domains of life[2]. In the molluscan CNS, the baseline level of ATP release can be increased following depolarization and application of serotonin, suggesting that ATP can act as an endogenous fast neurotransmitter[29]. The presence of ionotropic P2X ATP-gated cationic channels in peripheral chemosensory structures and the CNS (Fig. 1B) further support this hypothesis. However, we also reported $\mathrm{P} 2 \mathrm{X}$ receptors early in development, suggesting that ATP might be a paracrine signal molecule controlling cleavage and differentiation.

The purinergic sensory transmission is widespread in mammals[51] and might have deep evolutionary roots[2]. Mammalian P2X receptors[13] are comparable to their homologs in Aplysia based on sensitivity to ATP and kinetic parameters. The overall kinetic and pharmacological parameters of Aplysia P2X receptors are also similar to those described both in a close-related Lymnaea[30] and distantly related Schistosoma[28]. However, Lymnaea P2X showed much higher sensitivity ( $\mathrm{EC}_{50}$ is in $\mu$ molar range) to ATP, than Aplysia. Suramin and PPADS both inhibited the ATP evoked responses in other species[26-28,30], but in Aplysia, it occurred in a narrower range $(10-250 \mu \mathrm{M})$ than in Lymnaea $(0.1 \mu \mathrm{M}-250 \mu \mathrm{M})$.

Ecdysozoan $\mathrm{P} 2 \mathrm{X}$ receptors are relatively diverse. In contrast to Aplysia, the tick P2X receptor displayed a very slow current kinetics, and little desensitization during ATP application[26]. The tardigrade P2X[27] had a relatively low sensitivity for 
ATP $\left(\mathrm{EC}_{50} \sim 44.5 \mu \mathrm{M}\right)$, but fast activation and desensitization kinetics - similar to Aplysia.

Thus, Aplysia $\mathrm{P} 2 \mathrm{X}$ receptors exhibit a distinct phenotype, having a moderate ATP sensitivity (compared to the freshwater Lymnaea) but faster kinetics then some ecdysozoans. These "hybrid features" might be related to the marine ecology of Aplysia with a broader range of environmental changes.

Interestingly, the abundance of P2X receptors in the Aplysia (and kin) chemosensory systems (such as mouth areas, rhinophores, and gills) correlates with the expression of nitric oxide synthase[50,53-55] suggesting interactions of these afferent pathways in the control of feeding and respiration. Aplysia might also detect environmental ATP from bacterial and algal (food) sources[2] as in some other studied marine species, including lobsters[56].

Within the CNS of Aplysia, P2X receptors are expressed in the distinct cluster of insulin-containing neurons[46,52], likely associated with the systemic control of growth and, subsequently, reproduction. The release of the Aplysia insulin can decrease the level of glucose in hemolymph[52].
Moreover, F-cluster neurosecretory cells are electrically coupled[46], which help to synchronize their discharges and, eventually, the secretion of insulin. It is known that ATP can also be released from gap junction (innexins) and during synaptic exocytosis[2]. Thus, we can propose that P2X-induced neuronal depolarization of insulin-containing neurons provide positive purinergic feedback sustaining the excitability and secretory activity of this multifunctional bio-energetic center in Aplysia and related gastropods.

\section{Conflicts of interest}

The authors declare no conflict of interest.

Acknowledgments: We thank Dr. T. Ha and E. Bobkova for help with cloning and in situ hybridization. This work was supported by the Human Frontiers Science Program (RGP0060/2017) and National Science Foundation (1146575,1557923,1548121,1645219) grants to L.L.M.

\section{Role of authors:}

All authors had access to the data in the study and take responsibility for the integrity of the data and the accuracy of the data analysis. Research design, writing, acquisition of data: all authors. Molecular data: ABK, LLM; Pharmacological tests: JG; Analysis and interpretation: all authors: Funding: LLM. 


\section{Figures}
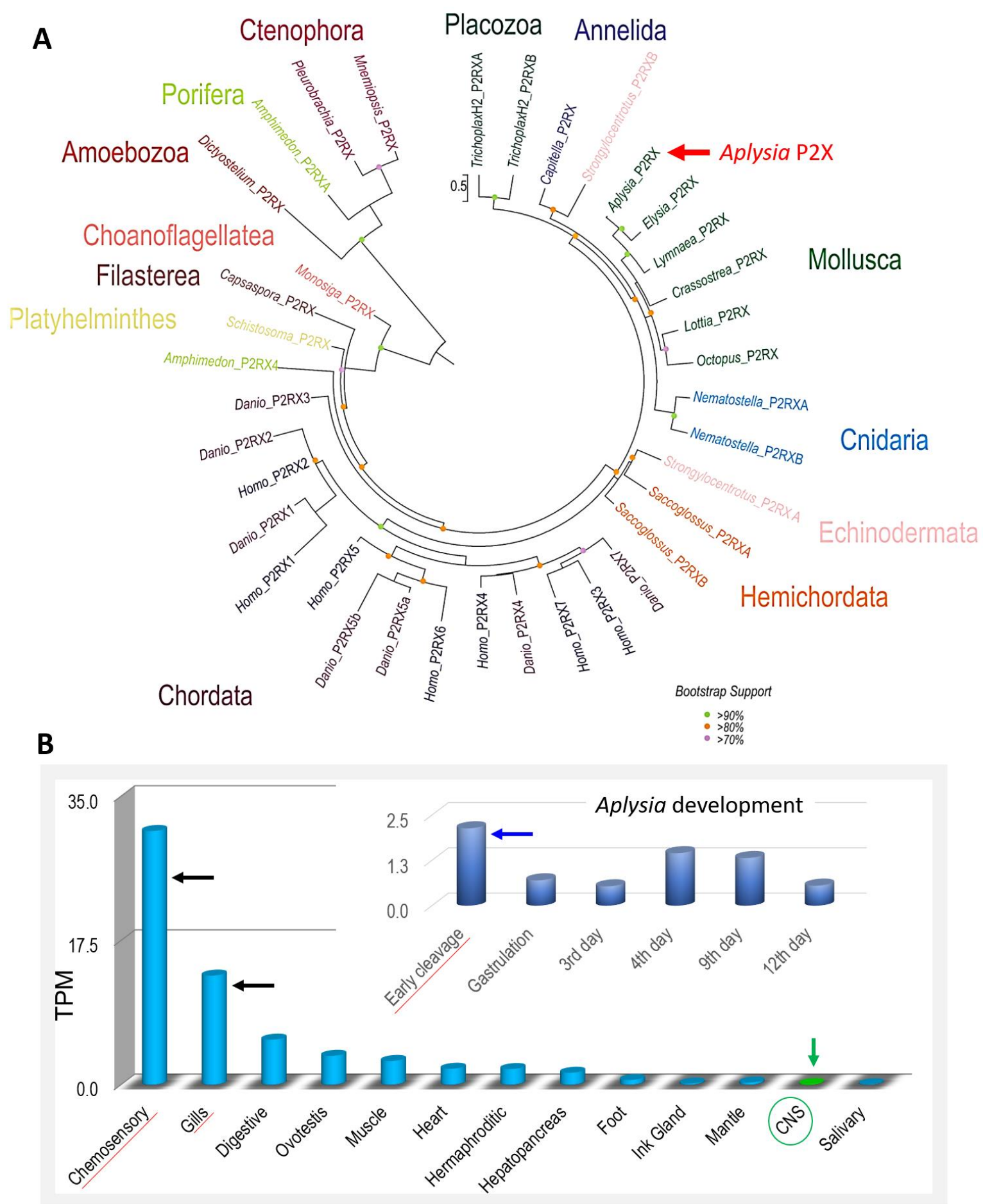

Adult Organs

Figure 1. A. Phylogenetic relationships of $P 2 X$ and P2X-like receptors (P2RX). A maximum likelihood (ML) phylogenetic tree of P2X receptors (Supplementary Data\#3 and excel table\#2 for sequences) with the best-fit model $(\mathrm{LG}+\mathrm{G})$. Bootstrap support less than 70 omitted. 
Phylogenetically, the P2RX predicted proteins cluster by phyla. P2X-type receptors are not unique to metazoans because they are detected in unicellular green algae Ostreococcus tauri[18], the amoeba Dictyostelium discoideum[17] the unicellular eukaryote Monosiga brevicollis[18] as well as Capsaspora owczarzaki[19] and all these species appear to have one P2X gene. Most of the non-bilaterians seem to have at least two P2X receptors (except for ctenophores, where only one receptor was detected). Lophotrochozoans, including the mollusc Aplysia and kins, appear to have one P2X receptor with different isoforms. The sea urchin and the acorn worm, Saccoglossus, both have at least two genes but numerous isoforms[1]. Humans[13], as well as other chordates, appear to have seven unique $\mathrm{P} 2 \mathrm{X}$ receptor genes[1]. B. Quantification of the expression of P2X receptors in the CNS, peripheral tissues, and developmental stages (insert) of Aplysia. The RNA-seq data represented as TPM (transcript per million) values[57-59]. The highest expression levels were detected in chemosensory areas (mouth areas and rhinophores), gills, and early developmental stages (Supplementary Data\#3 for SRAs). 

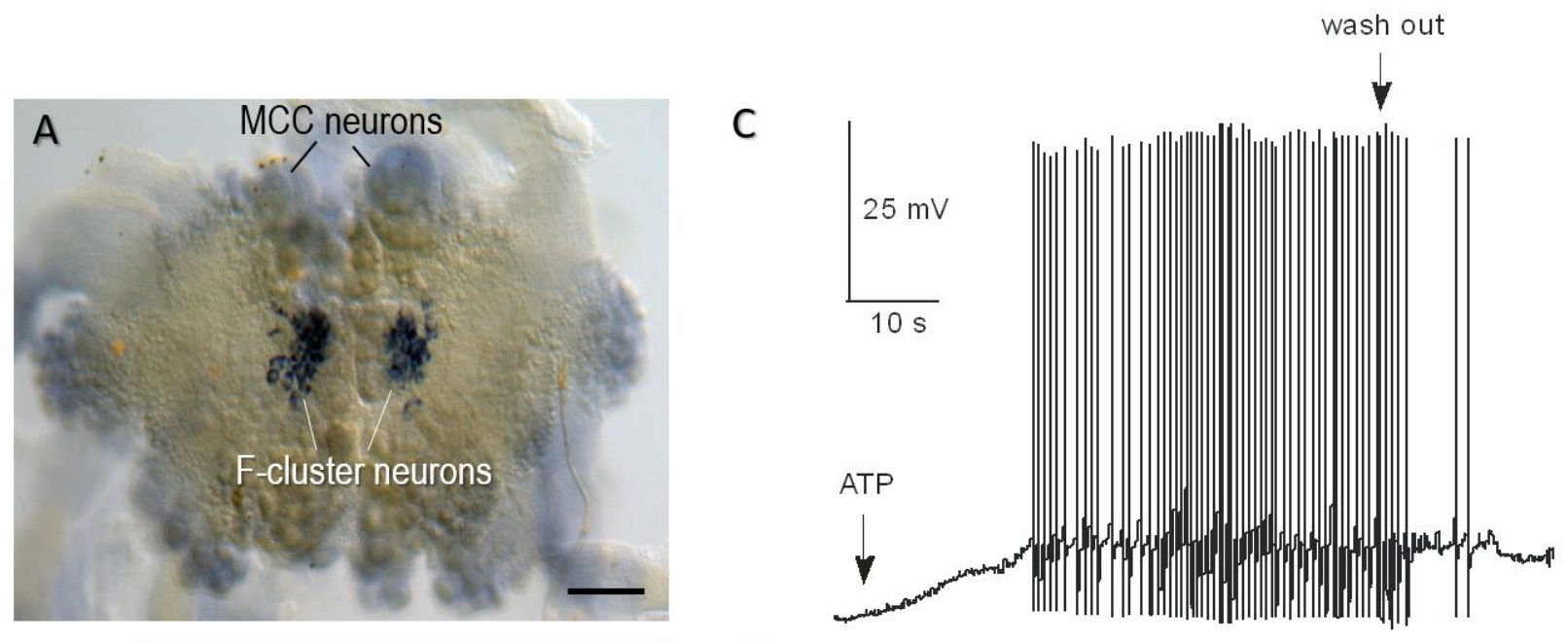

B

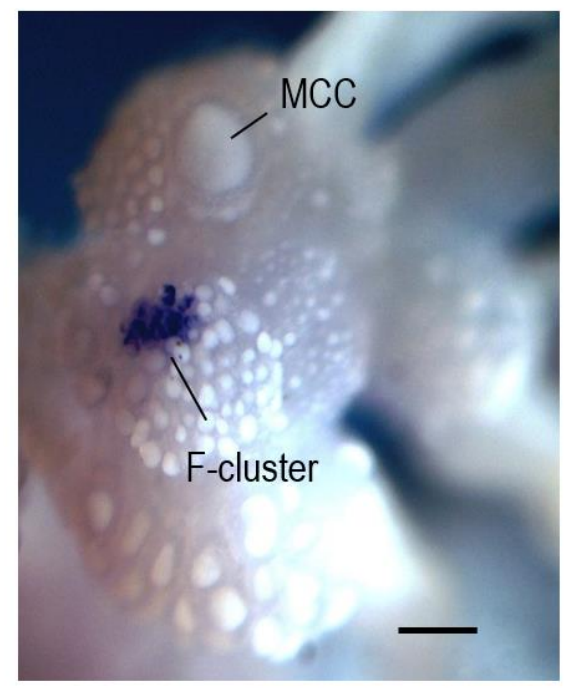

D

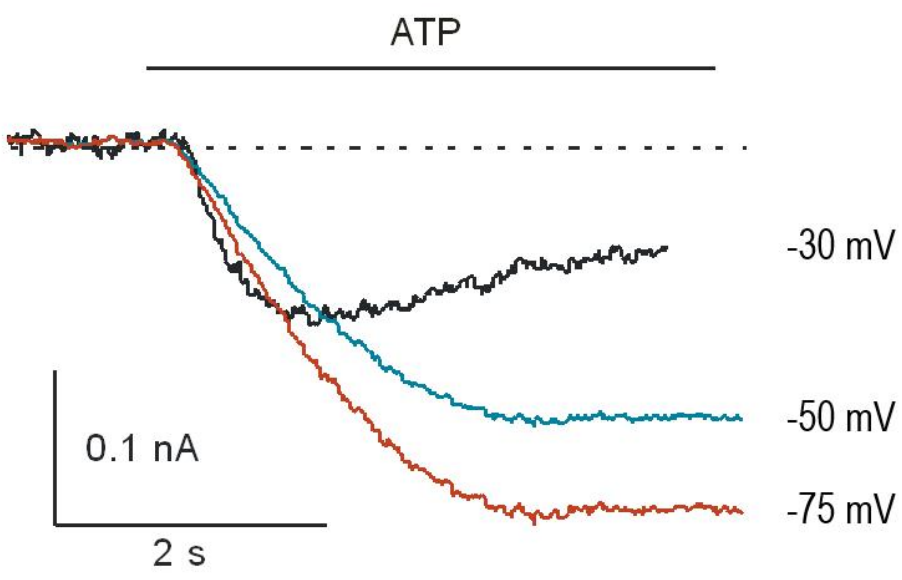

Figure 2. Distribution of AcP2X in the CNS of Aplysia and the effect of ATP on Aplysia Fcluster neurons. A and $\mathrm{B}$ : $A c \mathrm{P} 2 \mathrm{X}$ is expressed in neurons of the cerebral F-cluster (in situ hybridization). A pair of giant serotonergic feeding interneurons (MCC) are indicated by arrows. A. The preparation embedded in a mounting media. B. The cerebral ganglion photographed in $100 \%$ ethanol. Scale: $300 \mu \mathrm{m}$. C: Current-clamp recording from F-cluster neurons in the intact CNS. Bath application of ATP $(2.0 \mathrm{mM})$ caused an excitatory response with spiking activity (2$5 \mathrm{mV}$ depolarization with a burst of the action potentials), and full recovery following washout (indicated by arrows). D: Voltage-clamp recording from F-cluster neuron. Raw traces recorded in response to $2.0 \mathrm{mM}$ of ATP at three holding potentials (agonist application indicated by the line). 

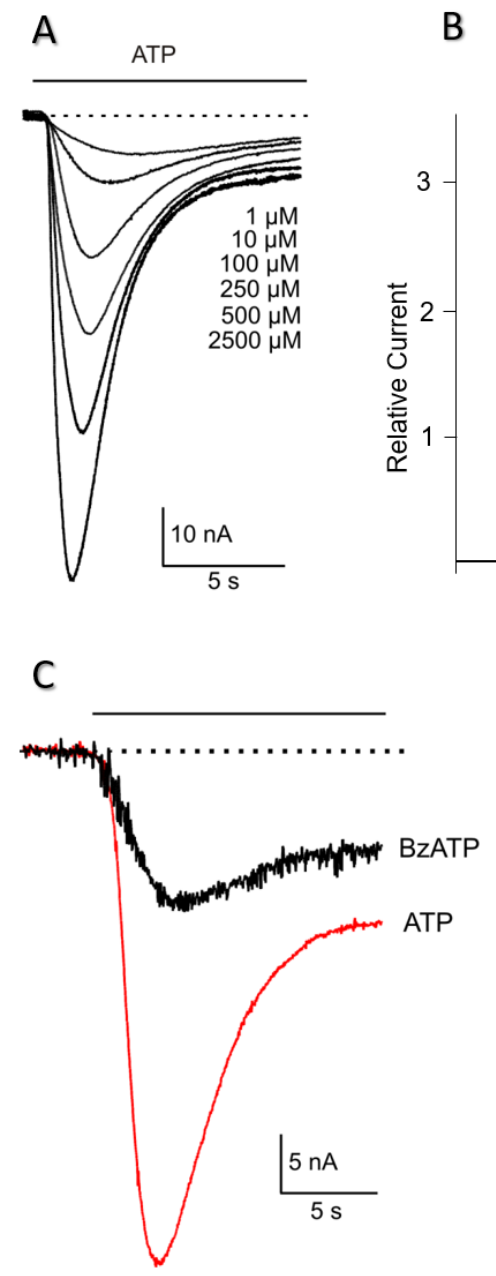

B

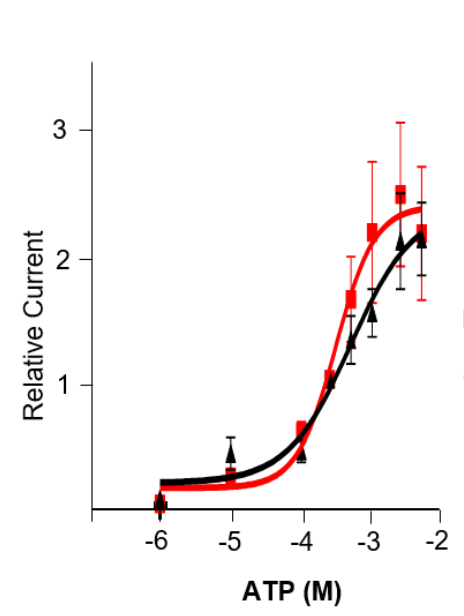

- Fast component

\ Slow component

D

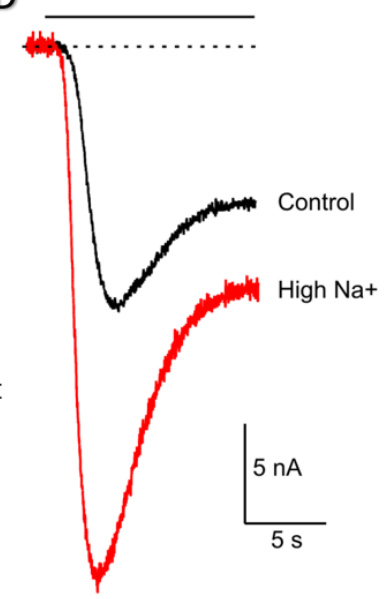

$\mathrm{E}$

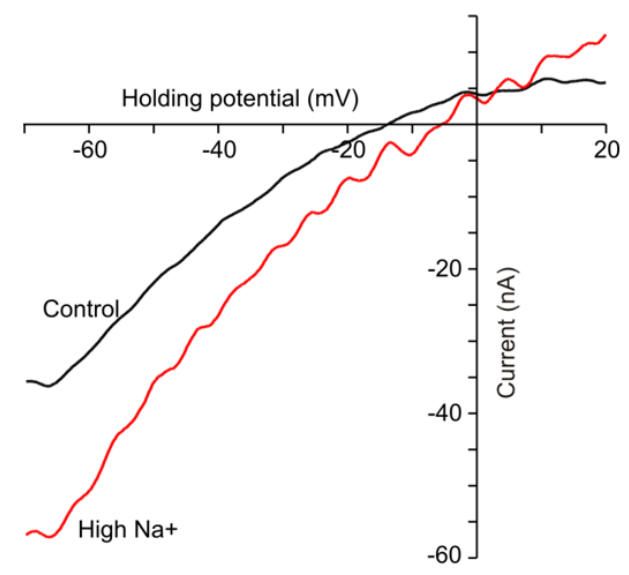

Figure 3. Functional expression of recombinant $A c P 2 X$ receptors in Xenopus oocytes. A: Examples of currents recorded in response to different concentrations of ATP (HP=-70mV, agonist application indicated by the solid line). B: Dose-response curves for ATP receptor activation. Mean currents were normalized to the response given by $250 \mu \mathrm{M}$ ATP ( $n=7$ oocytes). Serially increasing concentrations of ATP were applied to oocytes for 15s at 6-min intervals. Symbols represent mean \pm S.E. Continuous line for ATP represents data fitted using the equation I= $\mathrm{I}_{\max } /[1+(\mathrm{EC} 50 / \mathrm{L}) n H]$, where $\mathrm{I}$ is the actual current for a ligand concentration $(\mathrm{L}), n H$ is the Hill coefficient, and $\mathrm{I}_{\max }$ is the maximal current $\left(\mathrm{EC}_{50 \text { fast }}=306.0 \mu \mathrm{M}, \mathrm{EC}_{50 \text { slow }}=497.4 \mu \mathrm{M} ; n H_{\text {fast }}=1.58\right.$, $\left.n H_{\text {slow }}=0.97\right)$. C. Two-electrode voltage-clamp recordings from oocytes expressing AcP2X receptors. Representative inward currents recorded in response to ATP (red trace) and the $250 \mu \mathrm{M}$ of Bz-ATP (HP=-70mV, application indicated by the solid line). D: Recordings of ATP-induced current $(250 \mu \mathrm{M}, \mathrm{ATP})$ in the presence of normal $\left[\mathrm{Na}^{+}\right](96 \mathrm{mM})$ and with elevated extracellular $\mathrm{Na}^{+}(144 \mathrm{mM}$; red trace); HP=-70mV. E: Ramp voltage-clamp protocol from -70mV HP to $20 \mathrm{mV}$ in the presence of $250 \mu \mathrm{M}$ ATP. The plots of the subtracted current (a current in the presence of ATP minus the current in the absence of ATP) against voltage during the ramp. The red trace high $\left[\mathrm{Na}^{+}\right], 144 \mathrm{mM}$. According to the Nerst equation, the reversal potential was shifted by $10.2 \pm 1.3 \mathrm{mV}$ to the + direction of the holding potential. 

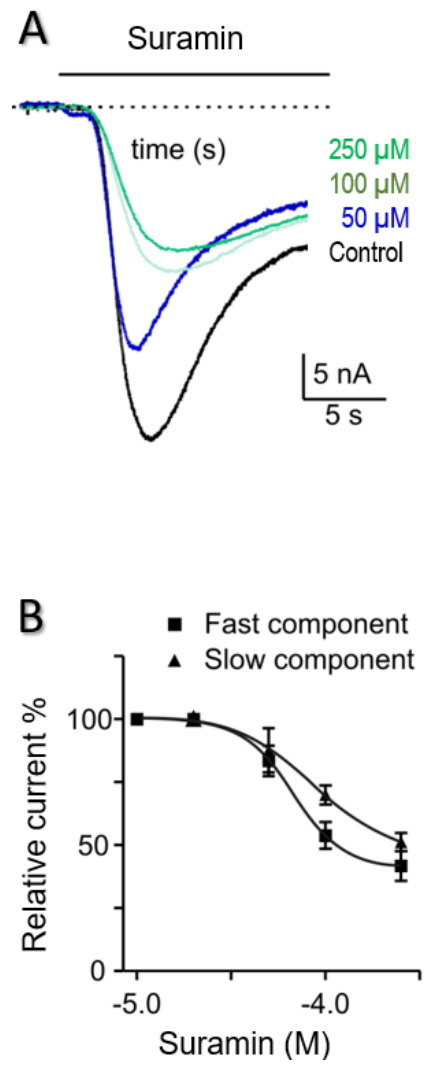
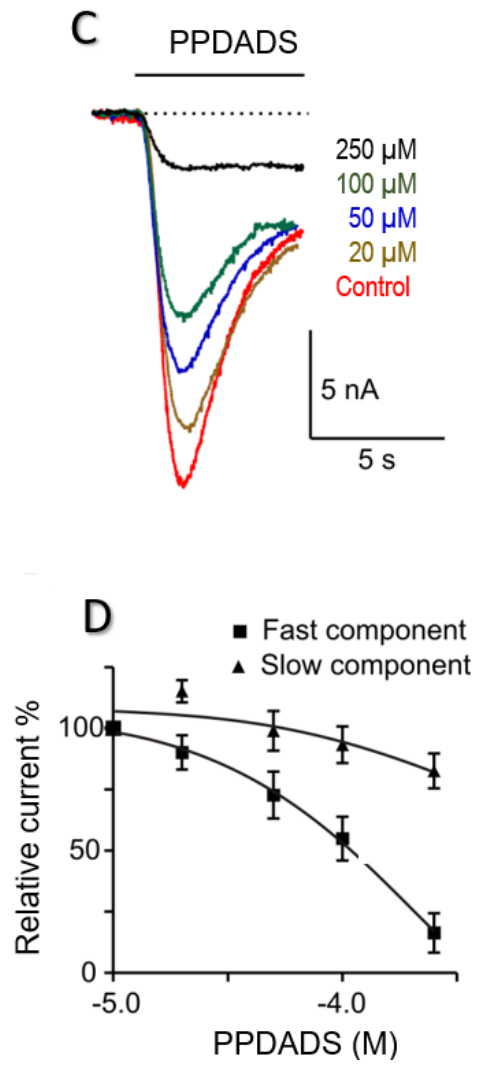

E

Antagonist Responses Summary

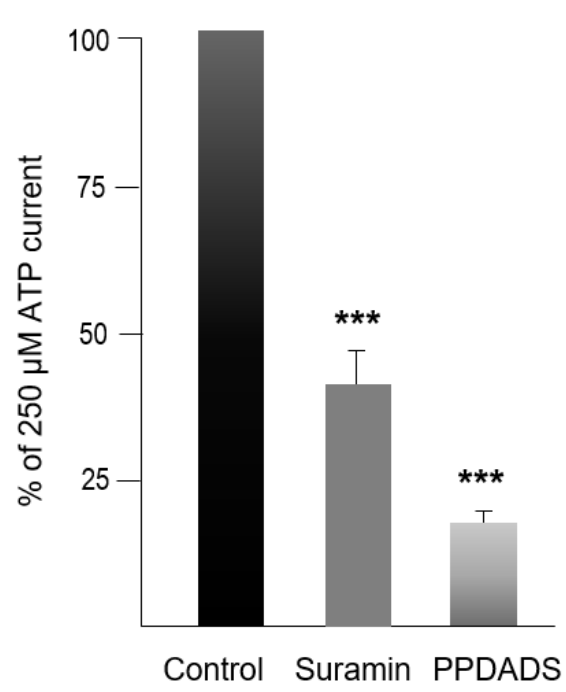

Figure 4. Pharmacology of AcP2X receptors in Xenopus oocytes. A: Example of currents induced by $250 \mu \mathrm{M}$ ATP. ATP was applied to oocytes for $15 \mathrm{~s}$, in the presence of varying concentrations of suramin $(\mathrm{HP}=-70 \mathrm{mV})$. B: Mean responses to $250 \mu \mathrm{M}$ ATP in the presence of 1$250 \mu \mathrm{M}$ suramin. There was a suramin-resistant component of the AcP2X current. Symbols represent mean \pm S.E. C: Traces recorded in response to $250 \mu \mathrm{M}$ ATP in the presence of varying concentrations of the second antagonist, PPADS (concentrations are shown in $\mu \mathrm{M}$, and all applications are indicated by the solid lines). D: Mean responses to $250 \mu \mathrm{M}$ of ATP in the presence of the PPADS (fast component of responses - closed squares, slow component - triangles). PPADS was an effective antagonist in the range of $1-250 \mu \mathrm{M}$. Fitting of the data using the sigmoidal doseresponse curve by a continuous line, $\mathrm{EC}_{50 \mathrm{fas}}=211$.2. Symbols represent the mean \pm S.E. $\mathrm{E}$ : Among the two antagonists tested, the suramin proved to be a more effective blocker of the ATP-activated channels. A chart of mean currents (\% of $250 \mu \mathrm{M}$ ATP response) in the presence of $250 \mu \mathrm{M}$ Suramin and $250 \mu \mathrm{M}$ PPADS. Mean currents were normalized to the response given by $250 \mu \mathrm{M}$ of ATP. Symbols represent mean \pm S.E; statistically significant differences (Student's $t$-test) from control $(\mathrm{P}<0.05)$ are indicated by asterisks $(* * *)$ above the bars. 


\section{References}

[1] Z. Hou, J. Cao, Comparative study of the P2X gene family in animals and plants, Purinergic Signal 12 (2016) 269-281. 10.1007/s11302-016-9501-Z.

[2] A. Verkhratsky, G. Burnstock, Biology of purinergic signalling: its ancient evolutionary roots, its omnipresence and its multiple functional significance, Bioessays 36 (2014) 697-705. 10.1002/bies.201400024.

[3] A.N. Drury, A. Szent-Gyorgyi, The physiological activity of adenine compounds with especial reference to their action upon the mammalian heart, The Journal of physiology 68 (1929) 213-237.

[4] P. Holton, The liberation of adenosine triphosphate on antidromic stimulation of sensory nerves, The Journal of physiology 145 (1959) 494-504.

[5] F.A. Holton, P. Holton, The capillary dilator substances in dry powders of spinal roots; a possible role of adenosine triphosphate in chemical transmission from nerve endings, J. Physiology 126 (1954) 124-140. [6] F.A. Holton, P. Holton, The vasodilator activity of spinal roots, J Physiol 118 (1952) 310-327. 10.1113/jphysiol.1952.sp004796.

[7] G. Burnstock, Purinergic nerves, Pharmacol Rev 24 (1972) 509-581.

[8] A. Huxley, Pain pathways, Nature 378 (1995) 658. 10.1038/378658b0.

[9] O.A. Krishtal, S.M. Marchenko, V.I. Pidoplichko, Receptor for ATP in the membrane of mammalian sensory neurones, Neuroscience Letters 35 (1983) 41-45. 10.1016/0304-3940(83)90524-4

[10] C.E. Jahr, T.M. Jessell, ATP excites a subpopulation of rat dorsal horn neurones, Nature 304 (1983) 730-733. 10.1038/304730a0.

[11] H.A. Kolb, M.J. Wakelam, Transmitter-like action of ATP on patched membranes of cultured myoblasts and myotubes, Nature 303 (1983) 621-623. 10.1038/303621a0.

[12] A. Surprenant, G. Buell, R.A. North, P2X receptors bring new structure to ligand-gated ion channels, Trends in neurosciences 18 (1995) 224-229. 10.1016/0166-2236(95)93907-f

[13] R.A. North, Molecular physiology of P2X receptors, Physiol Rev 82 (2002) 1013-1067. 10.1152/physrev.00015.2002.

[14] A.J. Brake, M.J. Wagenbach, D. Julius, New structural motif for ligand-gated ion channels defined by an ionotropic ATP receptor, Nature 371 (1994) 519-523. 10.1038/371519a0.

[15] S. Valera, N. Hussy, R.J. Evans, N. Adami, R.A. North, A. Surprenant, G. Buell, A new class of ligandgated ion channel defined by P2x receptor for extracellular ATP, Nature 371 (1994) 516-519. 10.1038/371516a0.

[16] R.A. North, M.F. Jarvis, P2X receptors as drug targets, Mol Pharmacol 83 (2013) 759-769. 10.1124/mol.112.083758.

[17] S.J. Fountain, K. Parkinson, M.T. Young, L. Cao, C.R. Thompson, R.A. North, An intracellular P2X receptor required for osmoregulation in Dictyostelium discoideum, Nature 448 (2007) 200-203. 10.1038/nature05926.

[18] S.J. Fountain, L. Cao, M.T. Young, R.A. North, Permeation properties of a P2X receptor in the green algae Ostreococcus tauri, J Biol Chem 283 (2008) 15122-15126. 10.1074/jbc.M801512200.

[19] X. Cai, P2X receptor homologs in basal fungi, Purinergic Signal 8 (2012) 11-13. 10.1007/s11302-0119261-8.

[20] S.J. Fountain, Primitive ATP-activated P2X receptors: discovery, function and pharmacology, Front Cell Neurosci 7 (2013) 247. 10.3389/fncel.2013.00247.

[21] M. Muller, A. Henrich, J. Klockenhoff, P.W. Dierkes, W.R. Schlue, Effects of ATP and derivatives on neuropile glial cells of the leech central nervous system, Glia 29 (2000) 191-201. 10.1002/(sici)10981136(20000201)29:3<191::aid-glia1>3.0.co;2-r.

[22] R.A. North, A. Surprenant, Pharmacology of cloned P2X receptors, Annu Rev Pharmacol Toxicol 40 (2000) 563-580. 10.1146/annurev.pharmtox.40.1.563.

[23] G. Burnstock, A. Verkhratsky, Evolutionary origins of the purinergic signalling system, Acta Physiol (Oxf) 195 (2009) 415-447. 10.1111/j.1748-1716.2009.01957.x. 
[24] H. Duan, S. Ni, S. Yang, Y. Zhou, Y. Zhang, S. Zhang, Conservation of eATP perception throughout multicellular animal evolution: Identification and functional characterization of coral and amphioxus P2X7like receptors and flounder P2X7 receptor, Dev Comp Immunol 106 (2020) 103641. 10.1016/j.dci.2020.103641.

[25] O. Hobert, The neuronal genome of Caenorhabditis elegans, WormBook, ed. The C. elegans Research Community, WormBook, 2013.

[26] S. Bavan, L. Farmer, S.K. Singh, V.A. Straub, F.D. Guerrero, S.J. Ennion, The penultimate arginine of the carboxyl terminus determines slow desensitization in a P2X receptor from the cattle tick Boophilus microplus, Mol Pharmacol 79 (2011) 776-785. 10.1124/mol.110.070037.

[27] S. Bavan, V.A. Straub, M.L. Blaxter, S.J. Ennion, A P2X receptor from the tardigrade species Hypsibius dujardini with fast kinetics and sensitivity to zinc and copper, BMC Evol Biol 9 (2009) 17. 10.1186/1471-2148-9-17.

[28] K.C. Agboh, T.E. Webb, R.J. Evans, S.J. Ennion, Functional characterization of a P2X receptor from Schistosoma mansoni, J Biol Chem 279 (2004) 41650-41657. 10.1074/jbc.M408203200.

[29] J.A. Gruenhagen, P. Lovell, L.L. Moroz, E.S. Yeung, Monitoring real-time release of ATP from the molluscan central nervous system, J Neurosci Methods $139 \quad$ (2004) 145-152. 10.1016/j.jneumeth.2004.03.008.

[30] S. Bavan, V.A. Straub, T.E. Webb, S.J. Ennion, Cloning and characterization of a P2X receptor expressed in the central nervous system of Lymnaea stagnalis, PLoS One 7 (2012) e50487. 10.1371/journal.pone.0050487.

[31] L.L. Moroz, Aplysia, Curr Biol 21 (2011) R60-61. 10.1016/j.cub.2010.11.028.

[32] E.R. Kandel, The molecular biology of memory storage: a dialogue between genes and synapses, Science 294 (2001) 1030-1038. 10.1126/science.1067020.

[33] E.R. Kandel, Behavioral Biology of Aplysia, W.H. Freeman and Company, San Francisco, 1979.

[34] E.R. Kandel, Cellular Basis of Behavior, W.H. Freeman and Company, San Francisco, 1976.

[35] L.L. Moroz, NeuroSystematics and Periodic System of Neurons: Model vs Reference Species at Single-Cell Resolution, ACS Chem Neurosci 9 (2018) 1884-1903. 10.1021/acschemneuro.8b00100.

[36] G.F. Striedter, T.G. Belgard, C.C. Chen, F.P. Davis, B.L. Finlay, O. Gunturkun, M.E. Hale, J.A. Harris, E.E. Hecht, P.R. Hof, H.A. Hofmann, L.Z. Holland, A.N. Iwaniuk, E.D. Jarvis, H.J. Karten, P.S. Katz, W.B. Kristan, E.R. Macagno, P.P. Mitra, L.L. Moroz, T.M. Preuss, C.W. Ragsdale, C.C. Sherwood, C.F. Stevens, M.C. Stuttgen, T. Tsumoto, W. Wilczynski, NSF workshop report: discovering general principles of nervous system organization by comparing brain maps across species, J Comp Neurol 522 (2014) 14451453. 10.1002/cne.23568.

[37] L.L. Moroz, J.R. Edwards, S.V. Puthanveettil, A.B. Kohn, T. Ha, A. Heyland, B. Knudsen, A. Sahni, F. Yu, L. Liu, S. Jezzini, P. Lovell, W. Iannucculli, M. Chen, T. Nguyen, H. Sheng, R. Shaw, S. Kalachikov, Y.V. Panchin, W. Farmerie, J.J. Russo, J. Ju, E.R. Kandel, Neuronal transcriptome of Aplysia: neuronal compartments and circuitry, Cell 127 (2006) 1453-1467. 10.1016/j.cell.2006.09.052.

[38] L.L. Moroz, A.B. Kohn, Do different neurons age differently? Direct genome-wide analysis of aging in single identified cholinergic neurons, Front Aging Neurosci 2 (2010). 10.3389/neuro.24.006.2010.

[39] A.B. Kohn, T.P. Moroz, J.P. Barnes, M. Netherton, L.L. Moroz, Single-cell semiconductor sequencing, Methods Mol Biol 1048 (2013) 247-284. 10.1007/978-1-62703-556-9_18.

[40] S.V. Puthanveettil, I. Antonov, S. Kalachikov, P. Rajasethupathy, Y.B. Choi, A.B. Kohn, M. Citarella, F. Yu, K.A. Karl, M. Kinet, I. Morozova, J.J. Russo, J. Ju, L.L. Moroz, E.R. Kandel, A strategy to capture and characterize the synaptic transcriptome, Proc Natl Acad Sci U S A 110 (2013) 7464-7469. 10.1073/pnas.1304422110.

[41] L.L. Moroz, A.B. Kohn, Single-neuron transcriptome and methylome sequencing for epigenomic analysis of aging, Methods Mol Biol 1048 (2013) 323-352. 10.1007/978-1-62703-556-9_21.

[42] S.H. Jezzini, M. Bodnarova, L.L. Moroz, Two-color in situ hybridization in the CNS of Aplysia californica, J Neurosci Methods 149 (2005) 15-25. 10.1016/j.jneumeth.2005.05.007. 
[43] L.L. Moroz, A.B. Kohn, Analysis of gene expression in neurons and synapses by multi-color in situ hybridization, in: G. Hauptmann (Ed.) In Situ Hybridization Methods, Neuromethods, Springer Science+Business Media, New York, 2015, pp. 293-317.

[44] C. Trapnell, B.A. Williams, G. Pertea, A. Mortazavi, G. Kwan, M.J. van Baren, S.L. Salzberg, B.J. Wold, L. Pachter, Transcript assembly and quantification by RNA-Seq reveals unannotated transcripts and isoform switching during cell differentiation, Nat Biotechnol 28 (2010) 511-515. 10.1038/nbt.1621.

[45] D. Kim, G. Pertea, C. Trapnell, H. Pimentel, R. Kelley, S.L. Salzberg, TopHat2: accurate alignment of transcriptomes in the presence of insertions, deletions and gene fusions, Genome Biol 14 (2013) R36. 10.1186/gb-2013-14-4-r36.

[46] S.S. Rubakhin, L. Li, T.P. Moroz, J.V. Sweedler, Characterization of the Aplysia californica cerebral ganglion F cluster, J Neurophysiol 81 (1999) 1251-1260. 10.1152/jn.1999.81.3.1251.

[47] L.L. Moroz, J. Gyori, J. Salanki, NMDA-like receptors in the CNS of molluscs, Neuroreport 4 (1993) 201-204. 10.1097/00001756-199302000-00022.

[48] A. Surprenant, G. Buell, R.A. North, P2X receptors bring new structure to ligand-gated ion channels, Trends in neurosciences 18 (1995) 224-229. 10.1016/0166-2236(95)93907-f.

[49] A. Heyland, Z. Vue, C.R. Voolstra, M. Medina, L.L. Moroz, Developmental transcriptome of Aplysia californica, J Exp Zool B Mol Dev Evol 316B (2011) 113-134. 10.1002/jez.b.21383.

[50] L.L. Moroz, Localization of putative nitrergic neurons in peripheral chemosensory areas and the central nervous system of Aplysia californica, J Comp Neurol 495 (2006) 10-20.

[51] A.V. Gourine, E. Llaudet, N. Dale, K.M. Spyer, ATP is a mediator of chemosensory transduction in the central nervous system, Nature 436 (2005) 108-111. 10.1038/nature03690.

[52] P.D. Floyd, L. Li, S.S. Rubakhin, J.V. Sweedler, C.C. Horn, I. Kupfermann, V.Y. Alexeeva, T.A. Ellis, N.C. Dembrow, K.R. Weiss, F.S. Vilim, Insulin prohormone processing, distribution, and relation to metabolism in Aplysia californica, J Neurosci 19 (1999) 7732-7741.

[53] L.L. Moroz, T.P. Norekian, T.J. Pirtle, K.J. Robertson, R.A. Satterlie, Distribution of NADPHdiaphorase reactivity and effects of nitric oxide on feeding and locomotory circuitry in the pteropod mollusc, Clione limacina, J Comp Neurol 427 (2000) 274-284.

[54] S.F. Cummins, D. Erpenbeck, Z. Zou, C. Claudianos, L.L. Moroz, G.T. Nagle, B.M. Degnan, Candidate chemoreceptor subfamilies differentially expressed in the chemosensory organs of the mollusc Aplysia, BMC Biol 7 (2009) 28. 10.1186/1741-7007-7-28.

[55] C.D. Bishop, A. Pires, S.W. Norby, D. Boudko, L.L. Moroz, M.G. Hadfield, Analysis of nitric oxidecyclic guanosine monophosphate signaling during metamorphosis of the nudibranch Phestilla sibogae Bergh (Gastropoda: Opisthobranchia), Evol Dev 10 (2008) 288-299. 10.1111/j.1525-142X.2008.00238.x. [56] R.K. Zimmer-Faust, ATP: a potent prey attractant evoking carnivory, Limnol Oceanogr 38 (1993) $1271-1275$.

[57] G.P. Wagner, K. Kin, V.J. Lynch, Measurement of mRNA abundance using RNA-seq data: RPKM measure is inconsistent among samples, Theory Biosci 131 (2012) 281-285. 10.1007/s12064-012-0162-3. [58] S. Zhao, Z. Ye, R. Stanton, Misuse of RPKM or TPM normalization when comparing across samples and sequencing protocols, RNA 26 (2020) 903-909. 10.1261/rna.074922.120.

[59] Z.B. Abrams, T.S. Johnson, K. Huang, P.R.O. Payne, K. Coombes, A protocol to evaluate RNA sequencing normalization methods, BMC Bioinformatics 20 (2019) 679. 10.1186/s12859-019-3247-x. 